University of Nebraska - Lincoln

DigitalCommons@University of Nebraska - Lincoln

\title{
A Case-Control Study of Hantavirus Pulmonary Syndrome during an Outbreak in the Southwestern United States
}

Paul S. Zeitz

Jay C. Butler

James E. Cheek

Michael C. Samuel

James E. Childs

Centers for Disease Control and Prevention, Atlanta, james.childs@yale.edu

See next page for additional authors

Follow this and additional works at: https://digitalcommons.unl.edu/zoonoticspub

Part of the Veterinary Infectious Diseases Commons

Zeitz, Paul S.; Butler, Jay C.; Cheek, James E.; Samuel, Michael C.; Childs, James E.; Shands, Lee A.; Turner, Richard E.; Voorhees, Ronald E.; Sarisky, John; Rollin, Pierre E.; Ksiazek, Thomas G.; Chapman, Louisa; Reef, Susan E.; Komatsu, Kenneth K.; Dalton, Craig; Krebs, John W. W.; Maupin, Gary O.; Gage, Kenneth; Sewell, C. Mack; Breiman, Robert F.; and Peters, C. J., "A Case-Control Study of Hantavirus Pulmonary Syndrome during an Outbreak in the Southwestern United States" (1995). Other Publications in Zoonotics and Wildlife Disease. 75.

https://digitalcommons.unl.edu/zoonoticspub/75

This Article is brought to you for free and open access by the Wildlife Disease and Zoonotics at DigitalCommons@University of Nebraska - Lincoln. It has been accepted for inclusion in Other Publications in Zoonotics and Wildlife Disease by an authorized administrator of DigitalCommons@University of Nebraska - Lincoln. 


\section{Authors}

Paul S. Zeitz, Jay C. Butler, James E. Cheek, Michael C. Samuel, James E. Childs, Lee A. Shands, Richard E. Turner, Ronald E. Voorhees, John Sarisky, Pierre E. Rollin, Thomas G. Ksiazek, Louisa Chapman, Susan E. Reef, Kenneth K. Komatsu, Craig Dalton, John W. W. Krebs, Gary O. Maupin, Kenneth Gage, C. Mack Sewell, Robert F. Breiman, and C. J. Peters 


\title{
A Case-Control Study of Hantavirus Pulmonary Syndrome during an Outbreak in the Southwestern United States
}

\author{
Paul S. Zeitz, * Jay C. Butler, James E. Cheek, \\ Michael C. Samuel, James E. Childs, Lee A. Shands, \\ Richard E. Turner, Ronald E. Voorhees, John Sarisky, \\ Pierre E. Rollin, Thomas G. Ksiazek, Louisa Chapman, \\ Susan E. Reef, * Kenneth K. Komatsu, Craig Dalton,* \\ John W. Krebs, Gary O. Maupin, Kenneth Gage, \\ C. Mack Sewell, Robert F. Breiman, and C. J. Peters
}

\begin{abstract}
Division of Field Epidemiology, Epidemiology Program Office, and Divisions of Bacterial and Mycotic Diseases, Viral and Rickettsial Diseases, and Vector-Borne Infectious Diseases, National Center for Infectious Diseases. Centers for Disease Control and Prevention. Atlanta. Georgia, and Fort Collins, Colorado; Headquarters West. Indian Health Service, Albuquerque, and New Mexico Department of Health, Santa Fe, New Mexico; Navajo Area Indian Health Service. Window Rock, and Arizona Department of Health Services, Phoenix, Arizona; Colorado Department of Health, Denver
\end{abstract}

\begin{abstract}
In May 1993, an outbreak of hantavirus pulmonary syndrome (HPS) occurred in the southwestern United States. A case-control study determined risk factors for HPS. Seventeen case-patients were compared with 3 groups of controls: members of case-patient households (household controls), members of neighboring households (near controls), and members of randomly selected households $\geqslant 24 \mathrm{~km}$ away (far controls). Investigators trapped more small rodents at case households than at near $(P=.03)$ or far control households $(P=.02)$. After the number of small rodents was controlled for, case-patients were more likely than household controls to hand plow (odds ratio [OR], 12.3; 95\% confidence interval [CI], 1.1-143.0) or to clean feed storage areas (OR, 33.4; 95\% CI, 1.7-666.0). Case-patients were more likely than near controls to plant (OR, $6.2 ; 95 \% \mathrm{CI}, 1.1-34.0)$ and more likely than far controls to clean animal sheds (OR, 11.9; 95\% CI, 1.4-103.0). Peridomestic cleaning, agricultural activities, and an increased number of small rodents at the household were associated with HPS.
\end{abstract}

Hantaviruses are trisegmented, single-stranded RNA viruses of the family Bunyaviridae [1-3]. Five hantaviruses with distinct clinical and epidemiologic features have been characterized: Hantaan, Seoul, Puumala, Dobrava, and Prospect Hill. Each has a single rodent species as its primary reservoir. Hantaviruses are primarily transmitted to humans by inhalation of aerosolized rodent urine, feces, or saliva or particulates contaminated by rodent excreta [4, 5]. Rarely, infection from rodent bites or scratches has been reported [6]. The incubation period of known hantaviruses ranges from 4 to 42 days (average, 12-16) [1-3]. Person-to-person transmission has not been documented with any hantavirus.

Received 17 August 1994; revised 10 November 1994.

Presented in part: 34 th Interscience Conference on Antimicrobial Agents and Chemotherapy, Orlando, Florida, 4-7 October 1994 (abstract J258).

Informed consent was obtained from all participants in this investigation.

Use of trade names is for identification only and does not imply endorsement by the US Public Health Service or by the US Department of Health and Human Services. The opinions expressed herein are those of the authors and do not represent those of the Indian Health Service or the US Public Health Service.

Reprints or correspondence: Dr. Paul S. Zeitz, US Agency for International Development, G/PHN/HN/CS, SA-18 Room 1200, Washington, DC 20523-1817.

* Present affiliations: US Agency for International Development, Washington, DC (P.S.Z.); National Center for Infectious Diseases, Centers for Disease Control and Prevention (CDC), Atlanta (C.D.); National Immunization Program, CDC (S.E.R.).

The Journal of Infectious Diseases 1995;171:864-70

(c) 1995 by The University of Chicago. All rights reserved. 0022-1899/95/7104-0015\$01.00
In May 1993, an outbreak of illness characterized by a prodrome of fever and myalgia followed by abrupt onset of respiratory distress and subsequently termed hantavirus pulmonary syndrome (HPS) was identified in the southwestern United States [7, 8]. Virtually identical genetic sequences were amplified from hantavirus-specific RNA extracted from tissues of case-patients and rodents (Peromyscus maniculatus) captured at their households, providing direct evidence that a previously unrecognized hantavirus was the etiologic agent [9]. During the epidemic period, an interagency team conducted a case-control study to identify risk factors for HPS to assist in formulating prevention strategies and to develop hypotheses for future investigation.

\section{Subjects and Methods}

Case definition. Suspected cases of HPS were solicited from clinicians, medical examiners, and infection control practitioners through facsimiles, mailings, newsletters, and the media and were reported to county and state health departments, the Indian Health Service, and the Centers for Disease Control and Prevention. A case of HPS was defined as clinical findings of unexplained adult respiratory distress syndrome, unexplained bilateral pulmonary interstitial infiltrates on chest radiograph and oxygen saturation $<90 \%$ on room air, or autopsy results compatible with noncardiogenic pulmonary edema with no other identifiable cause of death in a resident of New Mexico, Arizona, Utah, or Colorado, with onset of symptoms during 1 January to 19 July 1993 and laboratory confirmation of a recent hantavirus infection. 
Laboratory evidence of a recent hantavirus infection in humans was established by one or more of the following: positive serology (presence of hantavirus-specific $\operatorname{IgM}, \geqslant 4$-fold rise in IgG titer, or both) as measured by ELISA, positive reverse transcription-polymerase chain reaction for hantavirus RNA, and immunohistochemistry reactive for hantavirus antigen using methods previously described [9-11].

Case-control study. Case-patients were matched with persons $\geqslant 10$ years old in each of 3 control groups: noninfected members of the case household (household controls; $n=98$ ), noninfected members of the household closest to the case household who agreed to participate (near controls; $n=70$ ), and noninfected members of a randomly selected household $\geqslant 24 \mathrm{~km}$ ( $1.6 \mathrm{~km}$ in urban areas) from the case household (far controls; $n$ $=80$ ). Control households were matched with case households by location (urban or rural and on or off an American Indian reservation). Each control subject was asked to submit a blood specimen to be tested for evidence of hantavirus infection.

A standard questionnaire was used to collect data during personal interviews with case-patients and controls. Interviews were done during June and July 1993 to obtain information about activities during the 6 weeks before illness onset for casepatients and for the same period for matched controls. Surrogate interviews were conducted with a close family member for casepatients who had died. Interviews were in the subjects' primary language (English, Spanish, or an American Indian language). Interviewers were not blinded to the case status of interviewees.

During June through August 1993, rodents were trapped in and around case and control households and tested for serologic evidence of hantavirus infection using methods previously described [12]. The number of small rodents captured at each household was adjusted for trapping effort and the number of traps lost or sprung without capturing a rodent using the following formula: number of small rodents trapped $=$ [number of traps set - (number of sprung traps $\times 0.5)$ ] - number of traps missing.

Statistical analysis. Univariate odds ratios and 95\% confidence intervals were calculated by using a separate conditional logistic regression model for each independent variable. Exposure variables with $P \leqslant .25$ in the univariate analysis were included as candidate variables in multivariate conditional logistic regression models. For each of the 3 control groups, models were constructed to test the association between HPS and each of the following: rodent-human contact, agricultural activities, peridomestic cleaning activities, occupation, and host factors. Models controlling for the number of small rodents were constructed for the near and far control comparisons. A backward stepwise procedure was used (removal criteria, $P \leqslant .15$; reentry criteria, $P \leqslant .10$ ). Variables retained in any of these models were combined into single stepwise models for each control group. The final logistic regression models were rerun to include records with missing values on variables not retained in the stepwise models. The Wilcoxon signed-rank test was used to compare differences between the number of small rodents trapped and the seroprevalence of cross-reactive hantavirus antibodies in Peromyscus animals at matched case and control households. Data were entered into Epi-Info (version 5.01; CDC, Atlanta) and analyzed by STATA (release 3.0; Computing Resource Center, Santa Monica, CA).
Table 1. Demographic characteristics of HPS case-patients and controls.

\begin{tabular}{lcccc}
\hline & Case-patients & $\begin{array}{c}\text { Household } \\
\text { controls }\end{array}$ & $\begin{array}{c}\text { Near } \\
\text { controls }\end{array}$ & $\begin{array}{c}\text { Far } \\
\text { controls }\end{array}$ \\
\hline Sex & & & & \\
$\quad$ Female & $10(59)$ & $48(49)$ & $42(60)$ & $44(55)$ \\
$\quad$ Male & $7(41)$ & $50(51)$ & $28(40)$ & $36(45)$ \\
Race & & & & \\
$\quad$ American Indian & $11(65)$ & $79(81)$ & $50(71)$ & $67(84)$ \\
$\quad$ White & $5(29)$ & $13(13)$ & $13(19)$ & $13(16)$ \\
$\quad$ Hispanic & $1(6)$ & $3(3)$ & $7(10)$ & - \\
$\quad$ Unknown & - & $3(3)$ & - & - \\
Age, years & & & & \\
$\quad$ Median age & 35 & 33 & 30 & 35 \\
$\quad$ Range & $13-68$ & $10-99$ & $10-88$ & $11-82$ \\
$\quad$ Total & 17 & 98 & 70 & 80 \\
\hline
\end{tabular}

NOTE. Data are number (\%) unless stated otherwise.

\section{Results}

Of 21 eligible case-patients, 17 case-patients or their surrogates agreed to participate. The clinical course of 13 of the 17 case-patients has been previously described [8]. The median age of the case-patients was 35 years (range, 13-68). One to 4 cases occurred in each 2-week period from mid-March to mid-July. Ten case-patients (59\%) were female, and 11 (65\%) were American Indian. Sixteen case-patients (94\%) lived in a rural area, and 1 lived in a small town (population $<35,000$ ) [13] but visited a rural area each weekend. Ten case-patients $(59 \%)$ resided on American Indian reservations; of these, $5(50 \%)$ were female. Thirteen (76\%) case-patients died and surrogate interviews were conducted.

Four additional case-patients who resided in a single household declined to be interviewed. They were $20-27$ years old, were American Indian, and had onset of symptoms during April and May 1993. Two of these patients died of HPS. This was the only instance of clustering of $\geqslant 2$ patients within a household.

Case-control study. Of 282 eligible controls, 251 (89\%) agreed to participate. Of participating controls, 236 (95\%) tested negative for a recent hantavirus infection; 12 controls (5\%) were not tested. Two near controls and 1 far control ( $1.3 \%$ of all controls tested) had a detectable IgG antibody, suggesting past infection, and were excluded from the analysis. None showed serologic evidence of a recent hantavirus infection. Controls were similar to case-patients with respect to sex, race, and age (table 1).

Univariate analysis identified 22 exposure variables with $P$ $<.1$ when cases were compared with $\geqslant 1$ of the control groups (table 2). Age and sex were not associated with HPS. Case-patients were more likely than any control group to trap rodents in or around their household and to have handled dead mice; they were more likely than near and far controls to observe mice around the exterior of the home. Of the 60 persons who attempted rodent trapping, 55 reported 


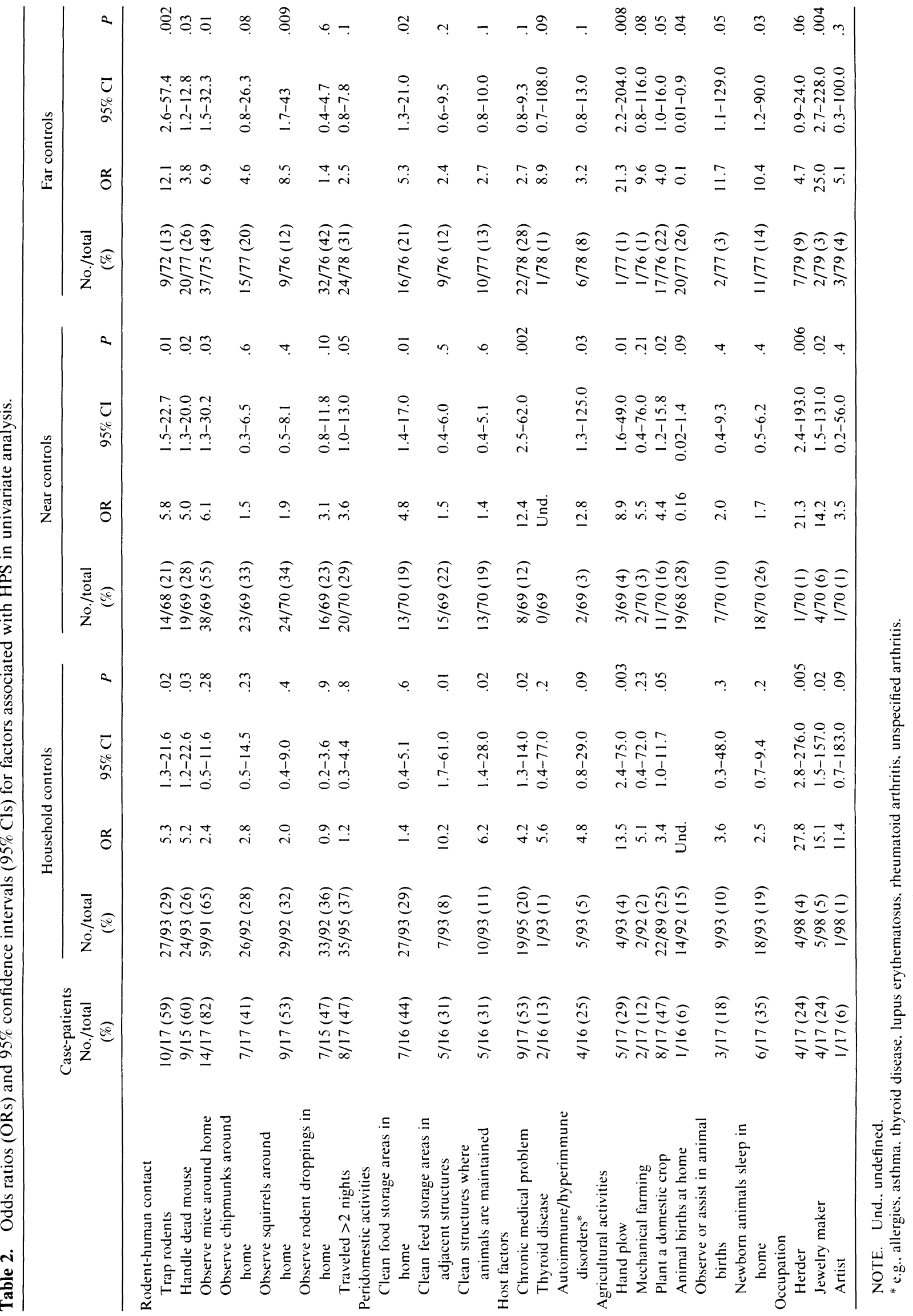


success. Human contact with other types of domestic or wild animals, whether alive or dead (rats, chipmunks, rabbits, prairie dogs, cats, dogs), was not associated with HPS. Sixteen case-patients (94\%) trapped rodents, observed rodents or their droppings in or around their household, or handled a dead mouse. The surrogate of 1 case-patient reported that the case-patient was scratched by a mouse. Harvesting piñon nuts and gathering of piñon nuts from rodent nests were not associated with HPS, and few cases or controls reported these activities.

Case-patients were more likely than persons in each control group to hand plow using a shovel or hoe and to plant a domestic crop. Mechanical plowing, rototilling, or animaldriven cultivation was not associated with HPS. Case-patients were more likely than household and near controls to report their occupation as herder. However, specific herding activities were not associated with HPS. Each of the 4 casepatients who reported their occupation as herder were American Indian. Occupation as a rancher, farmer, or construction worker was not associated with HPS. Twelve case-patients (71\%) did hand plowing or planting or reported their occupation as herder.

Case-patients were more likely than near or far controls to clean areas used for food storage in the household. Within case households, case-patients were more likely than household controls to clean adjacent structures (outbuildings) where food, grain, hay, or straw are stored or to clean adjacent structures where animals are kept. Seven case-patients (41\%) reported cleaning either type of structure. No associations were found with cleaning or straightening woodpiles, trash piles, or compost heaps. HPS case-patients were more likely to assist in animal births than were far controls.

Case-patients were more likely than household and near controls to report a nondisabling chronic medical problem and were more likely than near controls to report an autoimmune or hyperimmune disorder, such as allergies or asthma. Exposure to insects or ectoparasites (fleas, ticks, mosquitos, mites, gnats, lice) was not associated with HPS. There was no association between HPS and consumption of specific food (piñon nuts, unpasteurized milk, home-butchered meat, commodity foods). Recreational activities (running, hiking, hunting, fishing), domestic or occupational activities (weaving, wood gathering, hay hauling), group activities, traditional ceremonies, and travel were not associated with HPS.

Among all participants, female subjects (67\%) were more likely than male subjects (33\%) to clean food storage areas in the home, and males (61\%) were more likely than females $(39 \%)$ to handle a dead mouse. No other associations were found between subjects' sex and the risk activities identified. There were no associations between underlying chronic medical condition and risk activities.

Rodent trapping. More small rodents were trapped at case households than at near control $(P=.03)$ or far control $(P=.02)$ households (figure 1A). The seroprevalence of
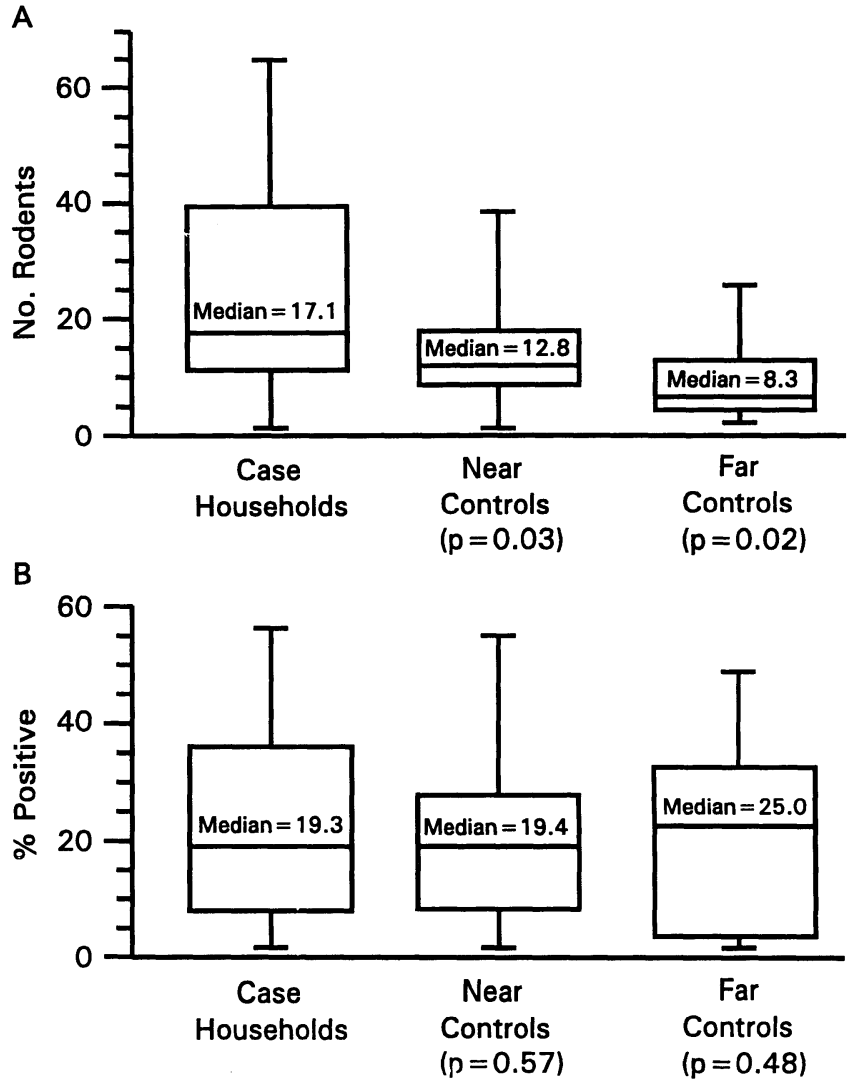

Figure 1. A, Number of small rodents trapped at case, near control, and far control households. B, Seroprevalence of hantavirus antibodies in Peromyscus species at case, near control, and far control households. Wilcoxon signed-rank $P$ value for comparison of findings from case households shown in parentheses.

hantavirus antibodies in Peromyscus animals was not significantly different between case and control households (figure 1B). Peromyscus rodents (P. maniculatus, deer mouse; $P$. truei, piñon mouse; $P$. boylii, brush mouse) were the most commonly captured $(68 \%, 1139 / 1687)$ and had the highest seroprevalence of hantavirus $(27 \%, 304 / 1139)$ [12]. Seropositive Peromyscus animals were trapped in and around the household of the 4 persons who declined to be interviewed.

Multivariate analysis. Results of analysis of variables retained in the final multivariate model for household controls and the final multivariate models controlling for the number of small rodents trapped at near and far control households are shown in table 3. Case-patients were more likely than household controls to hand plow and to clean feed storage areas in adjacent structures. Case-patients were more likely than near controls to plant a domestic crop and more likely than far controls to be a herder or to clean animal sheds.

\section{Discussion}

This study is the first to identify specific risk factors for HPS and the first epidemiologic investigation of any hanta- 
Table 3. Odds ratios (ORs) and $95 \%$ confidence intervals (95\% CIs) for factors associated with HPS in multivariate analysis controlling for the number of small rodents trapped at near and far control households.

\begin{tabular}{|c|c|c|c|c|c|c|c|c|c|}
\hline & \multicolumn{3}{|c|}{ Household controls* } & \multicolumn{3}{|c|}{ Near controls } & \multicolumn{3}{|c|}{ Far controls } \\
\hline & OR & $95 \% \mathrm{Cl}$ & $P$ & OR & $95 \% \mathrm{CI}$ & $P$ & OR & $95 \% \mathrm{CI}$ & $P$ \\
\hline Hand plow & 12.3 & $1.1-143$ & 0.05 & & & & & & \\
\hline Plant a domestic crop & & & & 6.2 & $1.1-34$ & .04 & 18.5 & $0.7-479$ & .08 \\
\hline Occupation as herder & 102.0 & $0.4-28,305$ & 0.1 & & & & 433.0 & $2.8-67.508$ & .02 \\
\hline Jewelry maker & & & & 7.3 & $0.5-117$ & .16 & & & \\
\hline $\begin{array}{l}\text { Clean feed storage areas in } \\
\text { adjacent structures }\end{array}$ & 33.4 & $1.7-666$ & 0.02 & & & & & & \\
\hline $\begin{array}{l}\text { Clean structures where } \\
\text { animals are maintained }\end{array}$ & 13.4 & $0.5-339$ & 0.1 & & & & 11.9 & $1.4-103$ & .02 \\
\hline Chronic medical problem & 7.0 & $0.9-54$ & 0.06 & 5.8 & $0.7-48$ & .1 & & & \\
\hline
\end{tabular}

${ }^{*}$ Household comparisons controlled for number of small rodents by study design.

virus to integrate rodent trapping data with interview data for cases and controls. Several findings emerged repeatedly from univariate and multivariate comparison of case-patients with 3 control groups: A greater number of small rodents at case households, contact with rodents, agricultural activities, and peridomestic cleaning activities were associated with HPS. These findings are the basis of guidelines for risk reduction.

Trapping rodents and handling dead mice was consistently associated with HPS in the univariate analysis. A larger number of small rodents were captured by investigators at case households than at control households. However, trapping rodents and handling dead mice by case-patients was not associated with HPS in the multivariate models controlling for the number of rodents captured by investigators, suggesting that case-patients may have been more likely than controls to trap rodents because they had a larger rodent infestation at the household. Handling trapped rodents may result in transmission, or placement of traps in enclosed spaces or other activities involved in trapping may allow inhalation of aerosolized rodent excreta or infected particulates. Similarly, planting, hand plowing, and peridomestic cleaning activities may expose persons to hantavirus through the activity or through removing needed tools or cleaning supplies from enclosed spaces.

Self-identification of occupation as a herder was associated with HPS; however, specific herding activities were not. This distinction suggests that activities of occupational herders, such as opening seasonally abandoned structures, may influence risk more than the activity of herding. In early spring, American Indian herders expand their herding range and reopen small structures such as hogans at "sheep camps" that have been closed during the winter. This type of risk is seen in Scandinavia, where vacationers opening vacant cabins are at increased risk for Puumala virus infection [2, 14]. In addition, laborers in China who camp in huts during seasonal agricultural work in grain fields are at higher risk of hantavirus infection [15].
The associations between nondisabling chronic medical conditions and HPS, including the association between a hyperimmune or autoimmune disorder and HPS in the univariate analysis, suggest that host factors may affect the development of HPS in some patients. An aberrant immune response could be part of an immunopathophysiologic mechanism of HPS in patients with a preexisting autoimmune or hyperimmune disorder, as is seen with lymphocytic choriomeningitis virus [16]. Most reported HPS patients have been 20-50 years of age, which is the same age group predominantly affected by other hantaviruses [17]. Lack of patients who are very young may reflect the role of the immune response in the pathophysiology of HPS.

Alternatively, the absence of cases among the very young and the elderly may reflect age-specific peridomestic or occupational activities associated with exposure. Many of the risk activities identified are common household chores that are not sex-specific, a finding supported by the nearly even number of male and female case-patients and the relatively few associations between sex and the risk activities identified. This is a distinct epidemiologic characteristic of newly recognized hantavirus-associated HPS in the southwestern United States, since other known hantaviruses predominantly affect males, presumably because of occupational risk activities [1$3,17]$.

The occurrence of the first recognized outbreak of HPS during spring and summer may be due in part to an increased likelihood of certain activities during these months. However, an unusual population increase of $P$. maniculatus during the spring of 1993 may be the most important factor for this outbreak [18]. Increased Puumala virus infection is seen in Scandinavia during years when the natural host (bank vole, Clethrionomys glareolus) is abundant [14, 19].

Only $1.3 \%$ of eligible controls had detectable levels of hantavirus IgG antibodies and none had IgM, suggesting that subclinical hantavirus infection in the Southwest is not common. This finding is consistent with a study of $>400$ persons 
who sought health care for mild illness during the 1993 outbreak, which showed an IgG seropositivity rate of 1.0\% [20]. In addition, serum samples collected in 1991 and 1992 from persons living in the outbreak area as part of a nutritional survey had an IgG seropositivity rate of $1.1 \%$ [21]. These findings suggest that infection with the newly recognized hantavirus has a very high likelihood of causing HPS. The prevalence of hantavirus antibodies in the Southwest is remarkably similar to the seroprevalence of $1.2 \%$ in persons living in areas where wild rat-associated hantavirus has been epidemic in China [22].

Differences in the risk factors identified in the comparisons with each of the 3 control groups in the univariate and multivariate analyses may be due to the small number of case-patients, the variable number of controls, or the heterogeneous nature of disease transmission. Case-patients and household controls lived in the same household; therefore, these comparisons allowed assessment of the association between HPS and various activities with the same potential for domestic rodent exposure. Comparisons between the casepatients and near and far controls allowed assessment of associations between HPS and the same activities with different levels of rodent population density.

Limitations of this study may include an ascertainment bias in the retrospective identification of cases, because autopsies are not routinely done on persons living in the area. A withdrawal bias may have been caused by the refusal of 4 case-patients to be interviewed. An interviewer bias may have been caused by the lack of blinding of interviewers to the case or control status of subjects. Recall bias from surrogate interviewing or from the widespread media coverage of the outbreak may have overestimated or underestimated the odds ratios.

The findings of this study suggest that eliminating rodents from human environments is the basis for prevention. Specific measures to reduce risk for hantavirus transmission include prevention of rodent entry into buildings, eradication of rodents from buildings, and removal of potential food sources and rodent nesting sites [23]. Cleaning and agricultural activities in rodent-infested areas should be done after ventilation and disinfection procedures have been followed. Heightened precautions, including the use of masks with high-efficiency particulate air filters, may be needed in heavily infested environments. Additional studies are needed to define the potential risk of activities in open versus closed spaces and the potential for household versus occupational exposure. These recommendations are most applicable for persons living in rural areas, as most HPS case-patients lived in or visited rural areas during their presumed incubation period. Sporadic cases of HPS caused by newly recognized hantaviruses continue to be identified over a wide area of the United States [24, 25]. Reduction of human exposure to rodents, rodent excreta, and contaminated particu- lates should decrease hantavirus-associated morbidity and mortality.

\section{Acknowledgments}

We thank Lori Armstrong, Michael Burkhart, Mark Carroll, Allen Craig, Ted Davis, John Doll, Russell Enscore, Paul Ettestad, T. Michael Fink, Ralph Fulgham, Maggie Gallaher, Peter Grauze, Richard Haskins, Susie John, Norton Kalishman, Ali Khan, Clare Kioski, Rima Khabbaz, Craig Levy, Harvey Lipman, Pat McConnon, Bernice Milane-Baca, Ben Muneta, Ron Moolenaar, Raymond Reid, Lola Riggs, Isaac Romero, Lawrence Sands, Herman Shorty, David Tibbs, Chuck Vitek, Gregory Wauneka, Minnie Yazzie, and all the community health representatives, epidemiologists, laboratory workers, physicians, public health nurses, sanitarians, and others for their time and effort in this investigation.

\section{References}

1. Johnson KM. Hantaviruses. In: Evans AS, ed. Viral infections of humans: epidemiology and control. 3rd ed. New York: Plenum Press, 1989:341-50.

2. McKee KT Jr, LeDuc JW, Peters CJ. Hantaviruses. In: Belshe URB, ed. Textbook of human virology. 2nd ed. St. Louis: Mosby Year Book, 1991:615-32.

3. Yanagihara R, Gajdusek DC. Hantavirus infection: a newly recognized viral enzootic of commensal and wild rodents in the United States. In: Notkins AL, Oldstone MB, eds. Concepts in viral pathogenesis III. New York: Springer-Verlag, 1989:291-6.

4. Nuzum EO, Rossi CA, Stephenson EH, LeDuc JW. Aerosol transmission of Hantaan and related viruses to laboratory rats. Am J Trop Med Hyg 1988;38:636-40.

5. Tsai TF. Hemorrhagic fever with renal syndrome: mode of transmission to humans. Lab Anim Sci 1987;37:428-30.

6. Dournon E, Moriniere B, Matheron S, et al. HFRS after a wild rodent bite in the Haute-Savoie and risk of exposure to Hantaan-like virus in a Paris laboratory [letter]. Lancet 1984; 1:676-7.

7. Centers for Disease Control and Prevention. Outbreak of acute illness-Southwestern United States, 1993. MMWR Morb Mortal Wkly Rep 1993;42:421-4.

8. Duchin JS, Koster F, Peters CJ, et al. Hantavirus pulmonary syndrome: a clinical description of 17 patients with a newly recognized disease. N Engl J Med 1994;330:949-55.

$\rightarrow$ Nichol ST, Spiropoulou CF. Morzunov S, et al. Genetic identification of a hantavirus associated with an outbreak of acute respiratory illness. Science 1993;262:914-7.

10. Ksiazek TG, Peters CJ, Rollin PE, et al. Identification of a new North American hantavirus that causes acute pulmonary insufficiency. Am J Trop Med Hyg 1995 (in press).

11. Feldmann H, Sanchez A, Morzunov S, et al. Utilization of autopsy RNA for the synthesis of the nucleocapsid antigen of a newly recognized virus associated with hantaviral pulmonary syndrome. Virus Res 1993;30:351-67.

12. Childs JE, Ksiazek TG, Spiropoulou CF, et al. Serologic and genetic identification of Peromyscus maniculatus as the primary rodent reservoir for a new hantavirus in the southwestern United States. J Infect Dis 1994;169:1271-80.

13. Economics and Statistics Administration, Bureau of the Census. Population and housing characteristics for census tracts and block number- 
ing areas, New Mexico. Washington, DC: US Department of Commerce, 1993.

14. LeDuc JW. Epidemiology of Hantaan and related viruses. Lab Anim Sci 1987;37:413-8.

15. Ruo SL, Li YL, Tong Z, et al. Retrospective and prospective studies of hemorrhagic fever with renal syndrome in rural China. J Infect Dis 1994; 170:527-34.

16. Buchmeier MJ, Welsh RM, Dutko FJ, Oldstone MBA. The virology and immunobiology of lymphocytic choriomeningitis virus infection. Adv Immunol 1980;30:275-331.

17. Xu ZY, Guo CS, Wu YL, Zhang XW, Liu K. Epidemiological studies of hemorrhagic fever with renal syndrome: analysis of risk factors and mode of transmission. J Infect Dis 1985;152:137-44.

18. Parmenter RR, Brunt JW, Moore DI, Ernest S. The hantavirus epidemic in the southwest: rodent population dynamics and the implications for transmission of hantavirus-associated adult respiratory distress syndrome (HARDS) in the four corners region. Albuquerque, NM: University of New Mexico, Department of Biology, 1993; Sevilleta LTER publication no. 41.

19. Nystrom K. Incidence and prevalence of endemic benign (epidemic) nephropathy in AC county, Sweden, in relation to population density and prevalence of small rodents. Acta Med Scand 1977; 609(suppl):1-92.

20. Simonsen L, Dalton MJ, Hennesey T, et al. Is there a mild course of hantaviral illness? [abstract]. Am J Epidemiol 1994;139(suppl):S82.

21. Centers for Disease Control and Prevention. Update: outbreak of hantavirus infection-southwestern United States, 1993. MMWR Morb Mortal Wkly Rep 1993;42:441-3.

22. Chen HX, Qiu FX, Dong BJ, et al. Epidemiologic studies on hemorrhagic fever with renal syndrome in China. J Infect Dis 1986; 154:394-8.

23. Centers for Disease Control and Prevention. Hantavirus infectionsouthwestern United States: interim recommendations for risk reduction, 1993. MMWR Morb Mortal Wkly Rep 1993;42:RR-11:1-13.

24. Centers for Disease Control and Prevention. Newly identified hantavirus-Florida. MMWR Morb Mortal Wkly Rep 1994;43:99, 105.

25. Centers for Disease Control and Prevention. Hantavirus pulmonary syndrome-northeastern United States, 1994. MMWR Morb Mortal Wkly Rep 1994;43:548-49, 555-6. 